\title{
A educação do corpo para o "soldado integral", "forte de físico, culto de cérebro e grande de alma"
}

\author{
Renata Duarte Simões ${ }^{1,2}$ \\ Silvana Vilodre Goellner ${ }^{3}$ \\ ${ }^{1}$ Núcleo Interdisciplinar de Estudos e Pesquisa em História da Educação/NIEPHE, \\ Faculdade de Educação, USP - Universidade de São Paulo, São Paulo, SP, Brasil \\ ${ }^{2}$ Grupo de Pesquisa Integralismo e outros movimentos nacionalistas, \\ UFF - Universidade Federal Fluminense, Niterói, RJ, Brasil \\ ${ }^{3}$ Centro de Memória do Esporte e Grupo de Pesquisa sobre Corpo e Cultura (GRECCO), \\ Escola de Educação Física, UFRGS - Universidade Federal do Rio Grande do Sul, Porto Alegre, RS, Brasil \\ Resumo: Este estudo reflete sobre o treinamento paramilitar realizado pela Milícia Integralista, unidade \\ armada da Ação Integralista Brasileira (AIB), principal partido de extrema direita no Brasil da década de \\ 1930, no sentido de formar o "soldado integral", "forte de físico, culto de cérebro e grande de alma". Analisa \\ os números do jornal Monitor Integralista, periódico doutrinário e prescritivo do movimento, encontrado no \\ Arquivo Público e Histórico do Município de Rio Claro, SP, e o jornal $A$ Offensiva, que se encontra \\ microfilmado na Biblioteca Nacional no Rio de Janeiro. Concluiu que o objetivo de Plínio Salgado, Chefe \\ Nacional da AIB, era treinar verbalmente, por meio de discursos, de propaganda boca a boca e pelo voto, \\ ou corporalmente, pela luta armada e corporal, os integralistas para torná-los aptos a defender as causas \\ do movimento.
}

Palavras-chave: Ação Integralista Brasileira; Milícia; educação do corpo.

The education of the body for an "integral soldier", "physically strong, intelligent and soul superior"

Abstract: This study examines the paramilitary training carried out by the Integralist Militia (Milícia Integralista), unit of the Brazilian Integralist Action (Ação Integralista Brasileira, AIB) of the extreme right wing political party in Brazil in the 1930s. The training was aimed to create the "integral soldier", a "physically strong, intelligent and soul superior" one. The study analyzes issues of the newspaper "Monitor Integralista", a prescriptive and dogmatic journal of the movement, found in the Public and History Archives of the city of Rio Claro, State of São Paulo, and in the "A Offensiva" newspaper, microfilmed an archived at the National Library of Rio de Janeiro. It concludes that Plínio Salgado's goal, the National Head of the AIB, was to train, by using verbal persuasion, speeches, word of mouth and by vote, by force and physical combat, the integralists to defend the causes of the movement.

Keywords: Brazilian Integralist Action; Militia; body education.

\section{Introdução}

A Ação Integralista Brasileira (AIB) foi oficialmente criada no dia 7 de outubro de $1932 \mathrm{e}$, desde seu princípio, esteve orientada por um forte sentimento nacionalista. Arquitetada por Plínio Salgado, trazia como finalidade primeira educar, disciplinar e preparar seus membros tornando-os soldados obstinados a defender a Nação. Considerando o cenário político da época, o integralismo expandiu-se rapidamente transformando-se em um importante partido político de extrema direita no país, contando, em 1937, segundo informações publicadas no Monitor Integralista, ${ }^{1}$ com mais de um milhão de adeptos ${ }^{2}$

\footnotetext{
${ }^{1}$ Monitor Integralista, ano V, n. 22, p. 4, 7 out. 1937.

${ }^{2}$ Nos diferentes acervos pesquisados não identificamos documentação de cunho historiográfico que explicitasse o número de filiados na AIB.
}

distribuídos em núcleos organizados em todo território nacional (SIMÕES, 2005; SIMÕES, 2009; TRINDADE, 1979; CAVALARI, 1999).

Dentre as várias ações propostas por Plínio Salgado, a AIB propunha ordenar as fileiras integralistas, 0 que foi efetivado mediante a estruturação de um conjunto de dispositivos composto por regras, normas e rituais a serem fielmente seguidos pelos seus membros. Essa ordenação instituía uma educação moral e corporal que ensinava ao militante a portar-se no movimento e na sociedade. Seus princípios estavam pautados pela submissão e obediência

Em função dessa ausência, tomamos como indicativo a contabilidade oficial do movimento, divulgada no Monitor integralista, mesmo sabendo da dificuldade historiográfica em ter como base analítica o discurso oficial de uma doutrina política. 
aos ideais do integralismo. Desse modo formavam-se os quadros do movimento, bem como sua Milícia especializada.

Considerando a expressividade da AIB no cenário político da época, esta pesquisa objetiva analisar o treinamento paramilitar realizado pela Milícia Integralista entre os anos 1932 e 1938, mais especificamente, no que diz respeito à formação do "soldado integral", "forte de físico, culto de cérebro e grande de alma". ${ }^{3}$ O recorte temporal adotado, que se estende de 1932 a 1938, justifica-se por ser, 1932, o ano de fundação da Ação Integralista Brasileira e, 1938, o ano de extinção da Associação Brasileira de Cultura $(A B C)$, antiga AIB. Vale lembrar que no início do Governo ditatorial de Getúlio Vargas todos os partidos políticos foram suprimidos, juntamente com eles a AIB, o que demandou uma readaptação das suas funções, levando-a a se transformar em sociedade civil com a denominação de Associação Brasileira de Cultura. Como ABC, funcionou até 1938 quando foi supostamente extinta, já que continuou funcionando na ilegalidade, e seus líderes foram enviados para o exílio.

Para realização deste estudo, tomamos como fontes primárias os jornais Monitor Integralista, periódico doutrinário e prescritivo do movimento, encontrado no Acervo Plínio Salgado do Arquivo Público e Histórico do Município de Rio Claro, SP, e $A$ Offensiva, jornal que se encontra microfilmado na Biblioteca Nacional no Rio de Janeiro. De A Offensiva, analisamos artigos, seções, colunas e pequenas notas dos 748 exemplares, publicados de 17/05/1934 a 19/03/1938, que foram catalogados por SIMÕES (2009). De o Monitor Integralista, analisamos 18 exemplares, publicados durante o período que se estende da primeira quinzena de 1933, n.1, a 7 de outubro de 1937, n. 22. Desse montante, consoante aos objetivos propostos para a elaboração desta pesquisa, selecionamos os textos que traziam informações sobre as instruções para a Milícia, bem como textos e fotos nos quais havia alguma menção a formação de seu grupamento.

Em A Offensiva, os primeiros artigos e notícias que mencionavam a existência da Milícia começam a aparecer na edição n. 6, publicada no dia 21 de junho de 1934, a qual noticia a

${ }^{3}$ A Semana Sportiva. A Offensiva, Rio de Janeiro, ano I, n. 26, p. 2, 8 nov. 1934. realização, no dia 11 de junho, na sede do Rio de Janeiro, de uma conferência com o secretário nacional da Milícia, Gustavo Barroso. Nesse periódico, as referências sobre a Milícia não tinham local fixo, eram publicadas de forma dispersa pelo jornal, em especial quando se fazia necessário convocar os militantes para um desfile, uma reunião, um treinamento ou, ainda, quando registrava a realização de algum evento que contava com a participação da Milícia ou que tenha sido por ela organizado. Já no jornal Monitor Integralista, o enfoque dado à Milícia é prioritariamente voltado para orientação, normatização e doutrinamento dos integrantes, sendo os textos publicados sequencialmente de modo a informar aos milicianos e dirigentes sobre os métodos de treinamento, sobre os regulamentos, etc.

Fundamentando-nos no aporte teórico da história cultural (CHARTIER, 2001; PESAVENTO, 2003; FALCON, 2002), dialogamos com as várias fontes de informações, buscando reconstruir o caminho adotado pelos integralistas para a construção e consolidação da sua Milícia, visto identificarmos que nesse espaço o integralismo exercia uma pedagogia assentada na educação do corpo, evidenciando, portanto, a edificação do "soldado integral: forte de físico, culto de cérebro e grande de alma". Como ferramenta metodológica foi utilizada a análise dos documentos em separado e, posteriormente, relacionados entre si. Desse entrecruzamento entre as diferentes fontes de pesquisa foram elaboradas unidades de significado que possibilitaram melhor compreender as ações empreendidas pelo integralismo para a formação, estruturação e exibição de sua Milícia, destacando, nesse processo, algumas ações voltadas para a educação corporal e moral de seus soldados.

\section{A formação da Milícia Integralista e a sua estruturação}

Pela defesa da Pátria e do Sigma, ${ }^{4}$ o integralismo aprovou, no $1^{\circ}$ Congresso Integralista Brasileiro, o regulamento do Departamento de Milícia Integralista que funcionou com uma estrutura inspirada nos moldes do exército e com atuação semelhante à

\footnotetext{
4 O Sigma era o sinal simbólico do integralismo. A letra grega corresponde ao "S" e indica o Somatório das Matemáticas. Baseado em Leibniz, que a escolheu para indicar a soma dos números infinitamente pequenos, Salgado empregou-a, em analogia aos membros da AIB, em camisas, bandeiras, faixas e outros aparatos propagandísticos e ritualistas.
} 
das brigadas paramilitares fascistas, conforme a orientação do seu organizador, o capitão Mourão Filho, que havia concluído o curso do EstadoMaior do Exército.

O Departamento da Milícia Integralista, criado em 1934, que mais tarde se tornaria Secretaria de Educação (moral, cívica e física), constituiu-se como um órgão cuja função maior era preparar os integralistas com base na cultura física, desenvolvendo um treinamento paramilitar que envolvia desde a instrução de "técnica, tática e moral" ${ }^{5}$ até a elaboração de planos de combate.

O processo de iniciação na militância do movimento desenvolvia-se na organização da juventude (plinianos), que envolvia crianças de quatro anos de idade até jovens de quinze. Contudo, para ingressar na Milícia era necessário que o "camisa-verde" ${ }^{6}$ tivesse completado dezesseis anos.

Responsável por controlar todas as Forças Integralistas $(\mathrm{FI})$, o Departamento de Milícia era considerado um dos fundamentais da AIB. Dirigido pelo Chefe Nacional, Comandante Supremo das FI de Terra, Mar e Ar, contava com a colaboração do Secretário Nacional, cargo ocupado por Gustavo Barroso, responsável pela Milícia Integralista e pela Tropa de Proteção, bem como do Chefe do Estado, responsável pela "[...] preparação e execução das decisões do alto Comando". 7 Essa estrutura se reproduzia também em âmbito regional com suas ramificações locais.

Apesar de Plínio Salgado ter mencionado, em diversos textos e discursos, ${ }^{8}$ que se opunha ao uso da força e da violência no processo de organização da Pátria e da Revolução Integralista, o integralismo não abdicou de treinar e armar sua Milícia com o argumento de que seria um órgão importante para efeitos de disciplinarização do militante e para manutenção da ordem dentro do próprio movimento. A imagem que buscava transmitir era a de que a AIB estava se armando, não para o combate, mas, contraditoriamente, para a conservação da paz.

\footnotetext{
${ }^{5}$ Regulamento Provisório para a Instrucção da Milícia Integralista (X).
Monitor Integralista, ano II, n. 7, p. 5, set. 1934 .
6 Os membros inscritos nas fileiras integralistas eram chamados de
"camisas-verdes" em função do uniforme composto por camisa na cor

${ }^{5}$ Regulamento Provisório para a Instrucção da Milícia Integralista (X).
Monitor Integralista, ano II, n. 7, p. 5, set. 1934 .
6 Os membros inscritos nas fileiras integralistas eram chamados de
"camisas-verdes" em função do uniforme composto por camisa na cor

${ }^{5}$ Regulamento Provisório para a Instrucção da Milícia Integralista (X).
Monitor Integralista, ano II, n. 7, p. 5, set. 1934 .
${ }^{6}$ Os membros inscritos nas fileiras integralistas eram chamados de
"camisas-verdes" em função do uniforme composto por camisa na cor

${ }^{5}$ Regulamento Provisório para a Instrucção da Milícia Integralista (X).
Monitor Integralista, ano II, n. 7, p. 5, set. 1934 .
6 Os membros inscritos nas fileiras integralistas eram chamados de
"camisas-verdes" em função do uniforme composto por camisa na cor verde que deveriam usar em todas as aparições públicas do movimento.

${ }^{7}$ Departamento de Milícia. Cap. I: dos Órgãos. Monitor Integralista, ano II, n. 6, p. 5, maio 1934.

${ }^{8}$ SALGADO, P. O debatido discurso do Chefe Nacional do integralismo no Club Commercial de SP. A Offensiva, Rio de Janeiro, ano II, n. 46, p. 3, 30 mar. 1935; SALGADO, P. A Offensiva, Rio de Janeiro, ano II, n. 62, p. 7, 20 jun. 1935.
}

Um texto publicado no jornal $A$ Offensiva, em 31 de maio de 1934, exemplifica essa afirmação, pois responde às críticas feitas por várias pessoas que assistiram à Parada Integralista, realizada no dia 20 de maio, cujo conteúdo denunciava os intentos armamentistas da AIB, fundamentalmente o potencial daquele "exército", a Milícia Integralista, caso viesse a se armar. Afirma $A$ Offensiva ser isso inevitável em função dos seus objetivos nacionalistas. Vejamos:

Se derem armas a esses homens, um verdadeiro exercito, o que acontecerá?

Se derem armas aos integralistas, e elles hão de possuil-as um dia, acontecerá que o Brasil será transformado numa grande Nação, numa grande Pátria... 9

Nogueira da Gama Filho, em defesa da imagem da Milícia, ainda argumentou em texto publicado em $A$ Offensiva, no dia 23 de março de 1935, página 4 , que se tratava menos de uma organização militarizada que de uma escola de civismo, de disciplina inteligente e de patriotismo sadio, inteiramente nova no Brasil. Nas suas palavras:

Milícia integralista! Escola de rythmo e
harmonia onde se acrysolam e se
homobenizam todas as virtudes do coração e
do entendimento. Milícia de homens livres,
escravos voluntários de um ideal sublime!
Escola de disciplina e de ordem onde cada um
traz dentro de si a noção perfeita do dever a
cumprir, o espírito de abnegação, a imagem do
sacrifício. [...] Nela o povo vibra de esperança,
ergue-se viril e forte, caminha de fronte erguida,
peito descoberto, passo firme, para uma
redempção gloriosa.

Embora os documentos apontem para a estruturação armamentista da Milícia, Plínio Salgado não admitia, em discursos voltados ao público não integralista, o uso de armas pelas tropas da AIB, afirmando constantemente em seus pronunciamentos que o movimento não tinha dinheiro para comprar armamentos, e que optaram pela revolução de ideias por estar o povo brasileiro fatigado de revoluções armadas: "O integralismo vencerá pela revolução das consciências, pela força do pensamento novo, pelo prestígio cultural e, principalmente, pela reforma interior". 10

Da análise da documentação investigada é possível descrever a estruturação e o funcionamento da Milícia, que se organizava em

\footnotetext{
${ }_{9}^{9}$ A Offensiva, Rio de Janeiro, ano I, n. 3, p. 1, 31 maio 1934.

${ }^{10}$ SALGADO, P. O debatido discurso do Chefe Nacional do integralismo no Club Commercial de SP. A Offensiva, Rio de Janeiro, ano II, n. 46, p. 3, 30 mar. 1935.
} 
quatro seções: a primeira ocupava-se da correspondência, do expediente, da estatística, da disciplina e da justiça (inquéritos e promoções); a segunda do serviço de informações; a terceira da instrução militar e elaboração dos planos de operações militares; e a quarta, do setor de material e serviços. A função da Milícia era preparar os "camisas-verdes" para atuar além dos desfiles e da cultura física, na medida em que pretendia desenvolver um treinamento militar, desde a instrução de "técnica, tática e moral" até a elaboração de planos de combate.

O Departamento de Milícia, inicialmente foi composto por Comando (órgão de direção) e Tropa (órgão de execução). A Tropa era dividida em Armas e Serviços. As Armas eram constituídas pelos integralistas combatentes de $1^{\underline{a}}$ e $2^{\underline{a}}$ linhas e a juventude, sendo a $1^{\text {a }}$ linha (de 18 a 45 anos) e $2^{\text {a }}$ linha (a partir de 45 anos); os Serviços eram constituídos pelos diferentes órgãos auxiliares e complementares das Armas.

As Armas poderiam ser infantaria, cavalaria, artilharia, engenharia e aviação. Os Serviços seriam de duas categorias: Provedores e Transportadores. Os Provedores seriam o Serviço de Saúde, o Serviço de Intendência, o Material Bélico, a Engenharia, o Correio, a Política e a Justiça. Os Serviços Transportadores seriam os Serviços de Transporte Terrestre (Serviço de Estrada de Rodagem e Ferrovia), Serviços de Transporte Marítimo e Fluvial. Hierarquicamente o Departamento de Milícia estava dividido em:

19) Graduados - Sub-Decurião, Decurião e Sub-Monitor;

$\left.2^{\circ}\right)$ Officiaes - Monitor Bandeirante e Mestre de Campo;

3) Officiaes Generaes - Brigadeiro, Tenente General e Chefe Nacional. ${ }^{11}$

Todo integralista com idade de 16 a 42 anos era obrigado a inscrever-se nas Forças Integralistas, optando pela categoria em que desejasse se engajar e pela qual realizaria um curso de instrução. Após preencher uma ficha onde ficariam registradas todas as suas aptidões, o candidato deveria assinar o juramento perante o comandante da Milícia e duas testemunhas, lendo-o em voz alta:

Assentando praça na Milícia Integralista, em nome de Deus e pela minha honra eu juro: ${ }^{11}$ Departamento de Milícia. Cap. IX: Da hierarquia. Monitor Integralista,
ano II, n. 6, p. 6, maio 1934. primeiro, absoluta disciplina aos meus chefes e perfeita solidariedade aos meus camaradas; segundo, dar a minha vida, se necessário, pela causa da Revolução Integralista; terceiro, amar, respeitar e fazer respeitar o Chefe Nacional. ${ }^{12}$

Com o cumprimento de sua instrução, o miliciano juraria bandeira em sessão solene no núcleo da $\mathrm{AIB}$, onde uma nova promessa de fidelidade ao Chefe seria prestada. Embora fosse denominado de "juramento às bandeiras", tratavase de uma declaração coletiva de submissão absoluta aos preceitos integralistas e a Plínio Salgado.

O ritual de juramento foi vastamente utilizado pela AIB como um modo de criar vínculos mais consistentes e de maiores comprometimentos de seus membros para com o movimento. $O$ ritual de jurar, assinar o juramento e fazê-lo frente a testemunhas reforçava ao integralista os deveres que assumiria com esse ato. $O$ juramento se dava sempre que alguém ingressasse no integralismo ou em algum de seus departamentos, bem como quando um integralista assumisse algum cargo no movimento ou mesmo mudasse de Núcleo. Os juramentos eram obrigatórios e sofreria penalidade quem se recusasse a executá-los, podendo acarretar, inclusive, na exclusão do militante do movimento.

O juramento, assim como a saudação integralista, previa a transmissão de valores e estilos de comportamento compatíveis com a concepção de sociedade e Estados integralistas. Inspirados nos movimentos fascistas europeus, os rituais eram articulados entre si para assegurar o aprendizado político-ideológico dos militantes, desde o nascimento até a idade adulta, por meio de um complexo conjunto ritualístico e de instrumentos de formação moral, intelectual, cívica e física. A tarefa fundamental desses rituais era criar o hábito da obediência aos chefes e de submissão às estruturas hierárquicas. Não se tratava, simplesmente, de copiar "certas formas exteriores do fascismo", mas de adotar os mecanismos básicos da formação totalitária fascista (TRINDADE, 1979, p. 188).

Para além da realização do juramento, ao ingressar na Milícia outros rituais tornavam-se obrigatórios. Um deles era o de conhecer os termos militares que eram empregados para organização das tropas, tais como: "coluna", "coluna por um", "fileira", "fila", "homem de base",

\footnotetext{
${ }^{12}$ Departamento de Milícia - Estado Maior. O alistamento da Milícia. Monitor Integralista, ano II, n. 6, p. 6, maio 1934.
}

Motriz, Rio Claro, v.18, n.2, p.327-337, abr./jun. 2012 
"linha", "frente", "formação", "intervalo", "distância", "profundidade", entre outros. ${ }^{13}$ Para além dos termos, era fundamental dominar os símbolos e os gestos que compunham o cotidiano da ação da Milícia, afinal, o comandante transmitia as ordens à sua tropa também por meio de gestos, silvos de apito e toques de corneta que seriam, esses últimos, utilizados tais como os do Exército Nacional. ${ }^{14}$

Visando estabelecer uma unidade de método na formação técnico-militar da Milícia, os dirigentes da AIB, orientados por Gustavo Barroso e Olympio Mourão Filho, elaboraram durante o $1^{\circ}$ Congresso Integralista Brasileiro, realizado em Vitória/ES, nos dias 28 de fevereiro, 1, 2, e 3 de março de 1934, o Regulamento para Instrução da Milícia Integralista, que, tendo sido aprovado no dia 2 pelo Chefe Nacional, deveria entrar imediatamente em execução. Na ocasião, Mourão Filho, Chefe do Estado-Maior da Milícia Nacional, e Barroso, Comandante Nacional da Milícia, foram designados para organizar e levar a funcionamento as novas estruturas estabelecidas no documento.

Cada um dos núcleos espalhados pelo Brasil recebeu uma cópia desse regulamento que também foi publicado nos jornais integralistas como meio de divulgar e fazer conhecer a instrução da Milícia pelos "camisas-verdes" de todo o País e do estrangeiro, devendo os núcleos fazer suceder com maior presteza possível as determinações no documento explicitadas.

No Regulamento para Instrução da Milícia Integralista estavam claramente expostas as estratégias traçadas pela AIB para atingir seus objetivos, apostando na educação do corpo como meio de se melhorarem as raças, tornando-as fortes e saudáveis, aperfeiçoando as qualidades morais e físicas. A AIB reconhecia a educação do corpo como essencial para o desenvolvimento da Nação e de seu ideário, além de funcionar como mecanismo de controle e cerceamento.

A educação do corpo deveria cumprir o papel de formar o integralista, tornando-o mais confiante, seguro e firme em suas decisões. Essas qualidades eram vistas como fundamentais ao soldado que se pretendia formar para defesa da "Nação Integral". Nesse sentido, a educação do corpo ainda era aplicada com a finalidade de

\footnotetext{
${ }^{13}$ Regulamento Provisório para a Instrucção da Milícia Integralista (X). Monitor Integralista, ano II, n. 7, p. 5, set. 1934.

14 Ibidem.
}

disciplinar os quadros integralistas e de militarizar seus membros para torná-los "soldados" obstinados a defender a Pátria, ou melhor, obstinados a defender os ideais integralistas.

\section{A educação do soldado integral: a exibição ordenada dos corpos}

A Milícia integralista, como foi anotado anteriormente, tinha como objetivo a formação do soldado integral. Essa formação prescindia de uma educação moral e corporal, afinal é no corpo que se inscreve a história pessoal de cada um e, também, de seu tempo. Uma das estratégias adotadas para tal intento residia na instrução técnico-militar e, sobretudo, na sua exibição pública efetivada mediante a realização de desfiles, paradas e eventos.

Por meio da instrução técnico-militar, o integralismo buscava disciplinar os seus membros conferindo coesão ao grupo de milicianos. A instrução técnico-militar era realizada a partir de três etapas que se davam concomitantemente: a instrução geral, a física e a militar propriamente. A instrução geral, "complemento da educação moral", tinha como objetivo a prática do miliciano no desempenho das missões que the fossem atribuídas na Milícia Integralista, ${ }^{15}$ tais como atividades esportivas, cívicas e de mobilização eleitoral, entre outras.

A instrução física abrangia os exercícios físicos propriamente ditos e o aproveitamento do valor físico de cada indivíduo nas diversas especialidades necessárias à ação dos milicianos nas lutas internas contra os inimigos da Pátria. ${ }^{16}$ No processo de militarização, a educação corporal foi utilizada como instrumento em prol da promoção da disciplina e da hierarquia. O enfoque da militarização do corpo, higienizado e eugenizado, era percebido como instrumento de transformação do corpo social. A nova higiene do corpo responsabilizava o indivíduo de modo a desenvolver uma consciência de bem-estar coletivo, enquanto a educação física voltava-se para obtenção de homens equilibrados e autossuficientes. As teorias eugênicas, por sua vez, buscavam argumentar que, com a disciplina dos músculos, se aperfeiçoaria a disciplina das vontades (LENHARO, 1986).

\footnotetext{
${ }^{15}$ Regulamento Provisório para a Instrucção da Milícia Integralista: objectivo e divisão da instrucção. (XXVII). Monitor Integralista, ano II, n. 7, p. 5 , set. 1934

${ }_{16}$ Regulamento Provisório para a Instrucção da Milícia Integralista: objectivo e divisão da instrucção. (XXVIII) Monitor Integralista, ano II, n. 7 , p. 5 , set. 1934
} 
O tema do esporte assumiu uma relevância particular no interior do discurso escrito ou figurativo do fascismo. É notória a importância que, especialmente no decorrer da década de 1930, a política de massas do regime atribuiu ao esporte enquanto fator de enquadramento e de formação do italiano do futuro. O esporte tornouse sinônimo de estilo de vida, "modo fascista de conceber e de levar a vida [...] de formar o caráter fascista" (MALVANO, 1996, p. 268). A ideia do jovem atleta era posta a representar a força, a vitória não só do atleta, mas também do regime.

O integralismo não ficou à parte dessas questões e buscou formar - inspirado no fascismo italiano, nos discursos médicos eugênicos e de fundamentação cristã do período - seus "soldados" para a defesa da Nação do ponto de vista "moral, intelectual e físico".

A militarização com auxílio de práticas esportivas era vista como possibilidade de assegurar os atributos morais do corpo e do "espírito" como a "sinergia, solidariedade, intrepidez, obediência, [...] senso de superioridade, ambição honesta, perseverança, confiança, consciência,..." (CALMON, apud LENHARO, 1986, p. 83).

Por sua vez, a instrução militar compreendia a instrução técnica e a instrução tática. A instrução técnica dizia respeito à "Ordem Unida", que objetivava proporcionar aos milicianos e às unidades os meios para que se movessem com perfeita ordem nas formaturas de apresentações, ensinar as técnicas do armamento e de uso material de toda a espécie que os milicianos tivessem que empregar, assim como treiná-los com exercícios de flexibilidade que visavam ensinar as formações e movimentos mais comuns na luta. ${ }^{17}$

A instrução tática visava ensinar a aplicação, em todas as circunstâncias de tempo e de espaço, dos conhecimentos adquiridos nos diversos ramos da instrução técnico-militar. ${ }^{18}$ Dividida em três períodos, a instrução se daria nos núcleos, dirigida pelos chefes de cada um deles, com auxílio dos milicianos mais "aptos". Compreenda-se que os mais aptos eram aqueles com maior vigor físico, que executavam os

\footnotetext{
17 Regulamento Provisório para a Instrucção da Milícia Integralista: objectivo e divisão da instrucção (XXX). Monitor Integralista, ano II, n. 7, p. 5 , set. 1934 .

18 Regulamento Provisório para a Instrucção da Milícia Integralista: objectivo e divisão da instrucção (XXXI). Monitor Integralista, ano II, n. 7, p. 5 , set. 1934 .
}

exercícios ministrados com mais agilidade, e que se mostravam dispostos a lutar até a morte, se preciso fosse, pelas causas do movimento. Não bastava que fosse forte de físico o miliciano, precisava estar disposto a ser obediente, abnegado, sacrificar-se $e$ ir às últimas consequências quando necessário, quando convocado por seus superiores. Sendo um "[...] homem devoto a Deus, à Pátria e à família", teria o integralista "[...] uma grande missão histórica a cumprir". ${ }^{19}$ A força do integralismo, segundo Plínio Salgado, residia na consciência do dever dos "camisas-verdes" para com o movimento e com a Pátria, obrigando-os aos maiores sacrifícios pelo bem do Brasil. ${ }^{20}$

O treinamento para que estivesse o miliciano instruído taticamente perduraria por nove meses, sendo dividido em $1^{\circ}, 2^{\circ}$ e $3^{\circ}$ períodos. No $1^{\circ}$ período, com duração de dois meses, o miliciano deveria aprender noções sucintas de organização e papel da Milícia no integralismo; deveres do miliciano; hierarquia na Milícia; movimentos individuais e em conjunto. ${ }^{21}$ Os movimentos eram exaustivamente treinados para que, em desfiles e solenidades, os integralistas mostrassem harmonia, uniformidade.

O $2^{\circ}$ período teria duração de três meses, e nele o miliciano continuaria a se aperfeiçoar nos exercícios de ordem unida; em ligeiros trabalhos de organização de terreno; nos conhecimentos e utilização do terreno; no conhecimento e utilização das armas de defesa individual; em noções sobre emprego de explosivos. ${ }^{22}$

No $3^{\circ}$ período, com duração de quatro meses, seria completado o período de instrução, com o ensinamento de tática dos pequenos combates, sobretudo nas cidades; pequenos trabalhos em campanha. $^{23}$

O ensino dos exercícios na Escola do Miliciano se dava por meio da repetição. Os milicianos eram reunidos em turmas e postos em fileiras conforme a natureza do exercício e o espaço disponível. $\mathrm{O}$ instrutor colocava-se à frente da

\footnotetext{
${ }^{19}$ Art. 229, Cap. XIX, Protocollos e Rituais: Da consciência do dever. Monitor Integralista, ano V, n.18, p. 70, 1937.

${ }^{20}$ Art. 229, Cap. XIX, Protocollos e Rituais: Da consciência do dever. Monitor Integralista, ano V, n.18, p. 70, 1937.

${ }_{21}$ Regulamento Provisório para a Instrucção da Milícia Integralista: objectivo e divisão da instrucção (XXXVII). Monitor Integralista, ano II, n. 7 , p. 5 , set. 1934

${ }^{22}$ Regulamento Provisório para a Instrucção da Milícia Integralista: objectivo e divisão da instrucção (XXXVIII). Monitor Integralista, ano II, n. 7, p. 5, set. 1934.

${ }^{23}$ Regulamento Provisório para a Instrucção da Milícia Integralista: objectivo e divisão da instrucção (XXXIX). Monitor Integralista, ano II, n. 7 , p. 5 , set. 1934 .
} 
turma de modo que pudesse ser visto e ouvido por todos. Lentamente, o movimento a ser executado era mostrado pelo instrutor. Em seguida, o instrutor repetia a execução e todos o acompanhavam. Por fim, solicitava aos milicianos que fizessem o exercício sozinhos e, com a ajuda dos auxiliares, realizavam as "correções das falhas". ${ }^{24}$

À medida que a turma fosse adquirindo a "perfeita correção necessária e energia na execução do movimento", ${ }^{25}$ receberia ordem para descansar. Assim que todos atingissem a perfeição na execução, o instrutor repetiria o movimento com a turma, exigindo cada vez mais rapidez e precisão.

Os exercícios deveriam ser executados precisamente, do mesmo modo como eram demonstrados pelo instrutor; caso contrário, seriam repetidos e corrigidos até que os executantes pudessem realizá-los perfeitamente. A "correção de atitude" era vista como possibilidade de garantir o equilíbrio de todas as partes do corpo, favorecendo o desenvolvimento físico do principiante e proporcionando o andar desembaraçado e marcial, ${ }^{26}$ ou seja, um marchar firme, similar ao realizado pelos militares, com fronte erguida, olhar a frente "mirando o futuro" e indicando que o "camisa-verde" deveria ter alta noção da própria dignidade, alcançada pela consciência do cumprimento dos seus deveres. ${ }^{27}$

Para além de gestos específicos e precisos, as marchas compunham o cenário da exibição das virtudes do soldado integral. Essas eram exaustivamente treinadas, pois protagonizavam muitos desfiles e solenidades públicas. A precisão no ato de marchar era extremamente exigida, devendo o executante treinar o tamanho dos passos $(75 \mathrm{~cm})$ e o ritmo com que deveriam ser realizados (120 por minuto). A execução das marchas se dava pelos comandos: ordináriomarche!; alto!; marcar-passo!; em frente!; trocarpasso!; passo sem cadência!; acelerado-marche!. A esses comandos, completavam-se os de voltas - direita volver!; esquerda volver!; meia volta-

\footnotetext{
${ }^{24}$ Regulamento Provisório para a Instrucção da Milícia Integralista: exercícios de Ordem Unida - Escola do Miliciano (XLI - XLV). Monitor Integralista, ano II, n. 7, p. 5, set. 1934.

${ }^{25}$ Regulamento Provisório para a Instrucção da Milícia Integralista: objectivo e divisão da instrucção (XLVI). Monitor Integralista, ano II, n. 7, p. 5 , set. 1934.

26 Regulamento Provisório para a Instrucção da Milícia Integralista: objectivo e divisão da instrucção (XLVII). Monitor Integralista, ano II, n. 7 , p. 5 , set. 1934

${ }_{27}$ Art. 229, Cap. XIX, Protocollos e Rituais: Da consciência do dever. Monitor Integralista, ano V, n.18, p. 70, 1937.
}

volver!; oitava à direita volver!. ${ }^{28} \mathrm{~A}$ repetição sistemática dos movimentos objetivava conduzir o principiante à execução automática e precisa.

A imagem do integralista "soldado", de pensamento uno e marcha precisa, era a que a AIB buscava apresentar incessantemente nos desfiles e aparições públicas. Na página 8 , da edição de número 2 de $A$ Offensiva, publicada no dia 24 de maio de 1934, Plínio Salgado teceu numerosos elogios à apresentação da Milícia no desfile realizado no Distrito Federal, no dia 20 de maio, no qual pode se observar a disciplina e entusiasmo de seus integrantes pela causa integralista em "tão poucos meses de instrucção".

O impacto que a exibição da Milícia proporcionava a quem assistisse seus desfiles foi tema de outra reportagem publicada em $A$ Offensiva no dia 10 de janeiro de 1935, página 35, a qual destaca que, ao desfilar pelas praças e ruas da Zona Sul do Rio de Janeiro, a Milícia ocasionou admiração dos moradores, que a elogiavam pela "correção e disciplina" demonstrada pelos integralistas. Nessa ocasião, um "grupo popular" acompanhou o desfile, seguindo na retaguarda.

A organização dos desfiles seguia um padrão estabelecido no Regulamento Provisório para a Instrucção da Milícia Integralista e que pode ser evidenciado na descrição do desfile realizado no dia 6 de janeiro de 1935, pela Milícia Integralista do Paraná que, como de praxe, apresentava a mesma rotina: primeiro o Chefe Provincial passou revista às tropas, seguindo-se "empolgante" cerimonial de juramento à bandeira $e$ de fidelidade ao Chefe Nacional. Prosseguiu-se $o$ ato com o cantar da primeira parte do Hino Nacional. ${ }^{29}$ Findados os discursos, ouviu-se a voz de marcha, dada pelo Mestre de Campo Comandante das tropas Egmar Schimmelpfeng. ${ }^{30}$ Esse ritual era seguido, basicamente, por todos os núcleos e visava unificar a exibição do soldado integral.

Para que as solenidades fossem realizadas com sucesso, Salgado argumenta que o miliciano,

\footnotetext{
${ }^{28}$ Regulamento Provisório para a Instrucção da Milícia Integralista: marchas. (LVI - LXVIII). Monitor Integralista, ano II, n. 7, p. 5-6, set. 1934.

${ }^{29}$ O Hino Nacional "sendo uma composição em louvor da Pátria", era considerado acima do hino integralista. Jamais poderia, contudo, se cantado na íntegra por qualquer membro da AIB, pois um integralista não admitiria a ideia de que o Brasil estivesse "[...] deitado eternamente em berço esplendido". A defesa era por uma Nação ativa, por um Brasil que não espera, que segue "Avante!". Imbuído de intenções, o discurso integralista tinha o intuito de convencer o "camisa-verde" a participar dinamicamente da construção da "Pátria Integral".

${ }^{30}$ A Offensiva, Rio de Janeiro, ano II, n. 35, p. 1, 10 jan. 1935
} 
quando convocado, deveria obedecer, invariavelmente, às determinações de seus superiores hierárquicos. Afinal, para a AIB, o bom miliciano era aquele que sabia obedecer sem discutir as regras de seus superiores; aquele que, demonstrando disciplina e coragem em suas ações, cumpriria, sem questionar ou deixar-se tomar pela curiosidade, as ordens que lhe fossem direcionadas. Nas suas palavras:

Ordem é ordem. Ordem não se discute. O miliciano não precisa saber para que foi convocado nem para onde vae, nem o que vae fazer. [...] Como poderá haver harmonia de movimento se não houver disciplina, se cada integralista não jurar que o trabalho pelo seu movimento será realizado 'executando sem discutir' as ordens recebidas do alto?[...] Quem quiser batalhar comnosco, venha soffrer comnosco e talvez possa morrer gloriosamente dirigindo a mais bella das orações a Deus. Porque a linguagem da fé se traduz no sacrifício e na luta e ella não faltará na acção dos que obedecem para servir a Pátria e a Deus. ${ }^{31}$

A ideia de redenção pela abnegação, pelo sofrimento e pelo sacrifício foi amplamente utilizada pelo movimento como meio de despertar a Nação e a alma de um povo. Segundo Plínio Salgado (1935, p. 197), "a alma de um povo só se desperta com sacrifício e dor". Essa proclamação reforçava a mística do sofrimento necessário aos indivíduos que atuavam em prol da salvação nacional.

A AIB difundia que o militante deveria estar consciente da possibilidade de ser perseguido e apontado como louco, podendo sofrer injustiças, ser incompreendido, injuriado e caluniado. Contudo, deveria permanecer forte e determinado nas ações que lhe fossem direcionadas. Apesar das perseguições, o integralista deveria continuar a "marchar com firmeza" rumo ao futuro, engrossando a massa dos que já tivessem sido contagiados pelas "idéias fascinadoras" (SALGADO, 1937, p. 88).

Como parte da pedagogia integralista, era ensinado aos seus adeptos que deveriam não apenas suportar resignadamente esse sofrimento, mas também dele se deleitar:

Aos verdadeiros integralistas não importa o término da luta, porque os inebria a própria luta [...]. Lutar: eis a grande alegria deste movimento. Encontrar dificuldades: eis a nossa volúpia. Sermos perseguidos: eis o motivo poemático. Sermos incompreendidos: eis um prazer singular que nos mostra uma

${ }^{31}$ SALGADO, P. O juramento. A Offensiva, Rio de Janeiro, ano I, n. 32 , p. 4,20 dez. 1934 superioridade deliciosa (SALGADO, 1937, p. 88).

A possibilidade de ser injustiçado era lembrada com frequência nas cerimônias integralistas com intuito de reforçar ao miliciano a percepção de que jamais poderia retroceder nas causas do movimento.

As cerimônias da Milícia Integralista eram, geralmente, precedidas pelo juramento à AIB e ao Chefe, lido por um "camisa-verde" e acompanhado pelos demais integrantes da Milícia que responderiam quando evocados. Com intuito de divulgar esse juramento e torná-lo de conhecimento de todos os militantes, A Offensiva do dia 24 de maio de 1934, n. 2, ano I, p. 8, o publicou em suas páginas:

Em nome de Deus, pela nossa Pátria, pela nossa família e pela nossa honra, nos juramos dar a nossa vida, se necessário, pela Revolução Integralista Brasileira, amar, respeitar e defender o Chefe Nacional, amar respeitar e defender as Bandeiras Nacional e integralista, symbolos da Pátria gloriosa e da idéia, juramos fidelidade à doutrina integralista e disciplina absoluta e sem exame, aos Chefes. Tropa em resposta: nós juramos!

Geralmente, as instruções à Milícia eram publicadas nos jornais integralistas em dias anteriores aos desfiles. A edição número 17 de $A$ Offensiva, datada de 6 de novembro de 1934, registrou, em sua primeira página, as instruções do comandante provincial da Milícia para os integralistas que desfilariam na comemoração do dia da Pátria. Informações sobre a organização, local de concentração, uniforme a ser utilizado e sobre 0 itinerário do desfile foram ali apresentadas.

Em aparições públicas, a estrutura da Milícia implantada em 1934 previa a seguinte formação com suas devidas unidades: decúria (formada por 10 militantes sob o comando de um decurião), o terço (três decúrias sob o comando de um monitor), a bandeira (quatro terços comandados por um bandeirante) e, finalmente, a unidade mais importante da Milícia, a legião, constituída por quatro bandeiras, sob o comando de um mestre de campo.

A decúria era a unidade fundamental de instrução. A formação dessa unidade era a de coluna por um. Nela, os milicianos deveriam guardar a distância, uns dos outros, medida pelo braço esquerdo estendido tocando as costas do miliciano da frente. $\mathrm{O}$ primeiro elemento, à frente do segundo, era a testa dos demais, a coluna 
deveria se organizar pela posição que ele ocupasse. O guia da marcha era o seu decurião.

Os alinhamentos e "coberturas" deveriam ser ensinados a homem por homem, fila por fila, elemento por elemento e, finalmente, a toda a decúria. Quando recebessem o comando de descansar, os homens deveriam alinhar-se e cobrir-se, retificando intervalos e distâncias, por um movimento rápido e instantâneo. ${ }^{32}$

Outro exemplo de como se dava a demonstração da educação do soldado integral pode ser evidenciado na primeira página de $A$ Offensiva de 21 de fevereiro de 1935, quando o jornal enfatiza uma concentração do Destacamento da Milícia do Distrito Federal, realizada na Quinta da Boa Vista, no qual destaca, outra vez, o "grande entusiasmo" dos integralistas que se reuniram em seus postos, "alegres" e "disciplinados", conscientes de sua missão.

Na ocasião, após realizada a solenidade das bandeiras e da vocalização do Hino Nacional, o Mestre de Campo Hollanda Loyola, ${ }^{33}$ Chefe do Estado Maior Provincial, fez a apresentação de seu Estado ao Brigadeiro Jeronymo Furtado do Nascimento, Chefe do Estado Maior Nacional, que elogiou publicamente Loyola pelo seu trabalho no comando, refletido na demonstração de disciplina e entusiasmo da Milícia.

Nogueira da Gama Filho destacou, no jornal $A$ Offensiva de 28 de fevereiro de 1935, elogios à Milícia por sua estruturação, organização e disciplina, conquistadas por meio da constituição de unidades permanentes, com seus oficiais graduados e milicianos em constante contato; a organização de legiões e grupos de legiões de comando e tropas estáveis; e a criação de uma Escola Provisória de Oficiais de Milícia, onde a oficialidade existente passou a receber "instrucção eficiente e indispensável". Segundo Gama Filho, essas medidas possibilitaram a

\footnotetext{
${ }^{32}$ Regulamento Provisório para a Instrucção da Milícia Integralista: em Marcha (XC). Monitor Integralista, ano II, n. 7, p. 6, set. 1934.

${ }_{33}$ Hollanda Loyola, renomado autor da educação física em âmbito nacional, editor e diretor do primeiro periódico específico da área, Revista Educação Physica, a partir de 1939, colaborador na constituição de métodos e programas de educação física para o Brasil, autor de 17 livros, todos eles publicados pela Companhia Brasil Editora e amplamente divulgados, ingressou para os quadros da AIB e redigiu para o jornal integralista artigos e crônicas sobre educação física e esportes que se fizeram presentes praticamente durante todo o período de existência de A Offensiva. Além disso, atuou como Mestre de Campo da Milícia e diretor da Escola de Intructores de Educação Physica do movimento. Sua vida e obra foram interrompidas em função de uma enfermidade e morte prematura em 1944. Contudo, apesar do curto período de tempo em que atuou na área, Loyola tornou-se uma referência importante para a Educação Física na transição dos anos de 1930 para os anos de 1940 .
}

divisão do trabalho, iniciando uma nova fase de atuação que perdurou até o ano seguinte. ${ }^{34}$

Gama Filho, assim como outros, revelou conferir grande parte desse sucesso ao trabalho realizado por Loyola à frente da Milícia, salientando a organização e a dedicação empregadas no treinamento dos "camisasverdes". Esse alcance se dera, segundo Nogueira, pelos esforços de concentração na constituição prática da Milícia, que era mais teórica. Os milicianos, que não se encontravam para a organização prática da Milícia, passaram a receber treinamento rotineiro e a ter contato constante.

Com o sucesso da Quinta da Boa Vista, a Milícia do DF consolidou o início de uma nova fase de operosidade, "brilhantismo e obediência às determinações do Chefe Nacional e pelo bem do Brasil". 35

Contudo, o próprio jornal destaca que nem sempre foi assim, nem sempre a Milícia Integralista demonstrou essa disciplina em seus desfiles. No ano de 1934, na "empolgante" Parada Integralista do dia 20 de maio, realizada no Rio de Janeiro, os milicianos, "desobedecendo" ao que Ihes foi "ordenado", chegaram ao local de concentração atrasados, muitos sem o uniforme, e mantiveram-se em conversas, desenfileirados, em total estado de "desorganização", postergando o início do desfile em três horas. O início do desfile, que estava marcado para as duas horas, só pode ser realizado às cinco da tarde. Os milicianos, refletiram os relatos, já estavam cansados e os comandantes exaustos. Esse fato só foi comentado um ano depois, no jornal do dia 28 de fevereiro de 1935, n. 42.

É provável que a desorganização do desfile tenha sido lembrada e comentada um ano depois, quando nem mais se recordaria de tal fato o leitor menos atento, para que a melhorias resultantes dos treinamentos da Milícia promovidos por Hollanda Loyola fossem colocadas em relevo, mostrando que muito havia sido feito pelo Mestre de Campo em prol da ordenação e coesão dos milicianos. Loyola atuou ativamente na AIB e mesmo após a sua extinção, em 1938, período em que o integralismo passou a funcionar na ilegalidade. Desse modo, contribui para que não só a Milícia, mas o movimento como um todo

\footnotetext{
${ }^{34}$ FILHO, N. G. Assumptos de Milícia. A Offensiva, Rio de Janeiro, ano II, n. 42, p. 4, 28 fev. 1935.

${ }^{35}$ Ibidem.
} 
passasse a pensar o corpo e todo o aparato para o seu treinamento e educação de modo obsequioso.

A Milícia e sua estrutura foram extintas em 4 de abril de 1935 pela Lei de Segurança Nacional, que definia os crimes contra a ordem política e social e conferia ao Governo Federal poderes especiais para reprimir atividades políticas ditas subversivas. A $1^{\underline{a}}$ Lei de Segurança Nacional (LSN), aprovada pelo Congresso, definiu como crimes: a greve de funcionários públicos; a provocação de animosidade nas classes armadas; a incitação de ódio entre as classes sociais; a propaganda subversiva; a organização de associações ou partidos com o objetivo de subverter a ordem política ou social por meios não permitidos em lei (FAUSTO, 2001, p. 196197). Promovendo o fechamento de entidades suspeitas e com fins armamentistas, o decreto determinou $\mathrm{o}$ encerramento das atividades da Milícia Integralista, fato protestado pela elite do movimento que passou a realizar o ritual "A noite dos tambores silenciosos", uma forma simbólica de os integralistas manifestarem seu desacordo pela extinção da Milícia pelo governo.

O Chefe Nacional explica o fim da Milícia em entrevista ao "Correio da Manhã", publicada em $A$ Offensiva do dia 20 de julho de 1935, página 7, na qual afirma que sua extinção se deu "[...] para evitar más interpretações dos hermeneutas communistas que se infiltraram no Partido Liberal". Para Salgado, essa ação foi necessária e pôs "[...] fim à Milícia que ensinava ao jovem o otimismo e a alegria, o entusiasmo e a juventude"; pôs fim "[...] a uma mobilização permanente, pronta a se por à disposição da ordem pública nos instantes em que essa estivesse ameaçada pelos golpes dos extremistas". ${ }^{36}$

Em 1936, a estrutura da extinta Milícia foi transplantada para a organização da juventude (os "Plinianos") quando seu Departamento se transformou em Secretaria Nacional de Educação (moral, cívica e física), que ficou responsável por prosseguir com o trabalho de organização e disciplinamento, iniciando a publicação de uma série de artigos "technicos sobre Educação Physica, com a finalidade de orientar as atividades dos soldados do Sigma, produzidos

${ }^{36}$ SALGADO, P. A Offensiva, Rio de Janeiro, ano II, n. 62, p. 7, 20 jun. 1935. pelo Secretário Provincial de Educação", ${ }^{37}$ Francisco de Assis Hollanda Loyola. ${ }^{38}$

Nessa ocasião, concomitantemente às atividades paramilitares, desenvolveram-se atividades esportivas, cívicas e de mobilização eleitoral. A AIB, aparentemente, abandonou suas pretensões "revolucionárias" e passou de uma posição antagonista em relação ao poder estabelecido para a de negociação, com vistas à candidatura de Salgado à Presidência da República, em 1937.

A linguagem militar foi substituída por uma nova terminologia, mas o essencial dos objetivos permaneceu 0 mesmo. As unidades denominavam-se então "turma, escola, bandeira, academia" e duas novas unidades foram criadas: "os grupos de academias", sob o comando de um Governo de Região, e a "Província", sob a direção do Secretário Provincial da Educação. Essa nova configuração permaneceu inalterada até 1937 quando todos os partidos políticos foram suprimidos, inclusive a Ação Integralista Brasileira que se transformou em uma sociedade civil que perdurou até 1938, quando foi extinta.

\section{Considerações finais}

A AIB utilizou inúmeros dispositivos para ordenar e disciplinar seus quadros, para disseminar as ideias e a doutrina integralista. A imagem que a AIB buscava propagar era a de um movimento harmônico, coeso, uno em sua forma de ser e de agir. Para tal, investiu na uniformização e no treinamento paramilitar de seus quadros. $O$ objetivo era treinar os integralistas para torná-los aptos a defender as causas do movimento de diversas formas, verbalmente, por meio de discursos, de propaganda boca a boca, pelo voto, ou corporalmente, pela luta corporal e armada.

Plínio Salgado criou a Milícia Integralista com treinamento específico para utilização de armas e explosivos, mas jamais admitiu publicamente que esses quadros estavam sendo treinados para combate. Em defesa do movimento, argumentava que ele venceria por meio de ideias.

Os "Regulamentos da Milícia", no entanto, apontam para intenções obscuras de vencer pelo uso da força. Assim, precisava fazer forte seu militante, física e intelectualmente, não para ele

\footnotetext{
${ }^{37}$ Monitor Integralista, ano V, p. 3, 10 abr. 1937.

${ }^{38}$ Com a Extinção da Milícia Integralista, Francisco de Assis Hollanda Loyola deixou de ocupar o cargo de Mestre de Campo, também extinto, e passou a ocupar o cargo de Secretário Provincial de Educação.
} 
se tornar consciente de seus atos, mas para ter conhecimento da ideologia e preceitos integralistas quando precisasse se manifestar e, principalmente, para se comportar como lhe era ordenado.

O papel paramilitar da Milícia e das tropas de serviços especiais é indelével na história do integralismo. Em diversas ocasiões ela entrou em ação nos conflitos de rua dos quais os de mais destaque ocorreram em: São Paulo - Bauru, em 3 de outubro de 1934; Largo da Sé na Capital, em 23 de novembro de 1934; no Rio Grande do Sul São Sebastião do Caí, em 24 de fevereiro de 1935. Eliminou, inclusive, em praça pública, um lituano que atentara contra a vida do Chefe Nacional, deixando transparecer que por trás do discurso apologético ao desarmamento, proferido pela AIB na figura de Plínio Salgado, o integralismo escamoteava os reais intentos revolucionários que se concretizaram pela disputa corpo a corpo e pelo uso de armas.

No jornal A Offensiva e no Monitor Integralista, os chefes hierárquicos divulgavam, enquanto durou a Milícia, as concentrações, os desfiles, os treinamentos, exaltando essas atividades, além de utilizarem o espaço para convocar os milicianos para esses encontros. Esse modo de divulgação estava assentado na exibição do soldado integral, sujeito capaz de defender a Pátria quando requerido para tal. Uma das estratégias utilizadas pela AIB estava ancorada na educação do corpo e pressupunha a precisão individual do gesto e a ordenação coletiva da marcha, a serem exibidos publicamente de modo a evidenciar a disciplina e a devoção: virtudes necessárias às atitudes fanáticas e, por assim ser, conservadoras.

\section{Referências}

CAVALARI, R. M. F. Integralismo: ideologia e organização de um partido de massa no Brasil (1932-1937). São Paulo: EDUSC, 1999.

CHARTIER, R. Textos, Impressão, Leitura. In: HUNT, L. (Org.) A Nova História Cultural. 2. ed. São Paulo, Martins Fontes, 2001.

FALCON, F. C. História cultural: uma nova visão sobre a sociedade e a cultura. Rio de Janeiro: Campus, 2002.

FAUSTO, B. História do Brasil. 9. ed. São Paulo: Edusp, 2001.

LENHARO, A. Sacralização da Política. 2. ed. São Paulo: Papirus, 1986.
MALVANO, L. O mito da juventude transmitido pela imagem: o fascismo italiano. In: LEVI, Giovanni; SCHIMITT, Jean-Claude. História dos jovens $2^{\circ}$ : a época contemporânea. São Paulo: Companhia das letras, 1996. p. 259-290.

PESAVENTO, S. J. História \& História Cultural. Belo Horizonte: Autêntica, 2003.

SALGADO, P. Despertemos a Nação. Rio de Janeiro: José Olympio, 1935.

SALGADO, P. Páginas de combate. Rio de Janeiro: José Olympio, 1937.

SIMÕES, R. D. Integralismo e Ação Católica: sistematizando as propostas políticas e educacionais de Plínio Salgado, Jackson de Figueiredo e Alceu Amoroso Lima no período de 1921 a 1945. 2005. 161 f. Dissertação (Mestrado em Educação) - Programa de Pós-Graduação em Educação: História, Política e Sociedade, Pontifícia Universidade Católica de São Paulo, PUCSP, São Paulo.

SIMÕES, R. D. A Educação do Corpo no Jornal A Offensiva (1932 - 1938). 2009. $205 \mathrm{f}$. Tese de Doutorado (Doutorado em História da Educação e Historiografia) - Faculdade de Educação da Universidade de São Paulo, FEUSP, São Paulo.

TRINDADE, H. Integralismo: o fascismo brasileiro na década de 30. São Paulo: Difiel, 1979.

Agradecimentos à Prof. ${ }^{a}$ Dr. ${ }^{\text {a }}$ Diana Vidal pelo auxílio prestado no processo de elaboração deste estudo. Pesquisa financiada pela FAPESP.

\section{Endereço:}

Renata Duarte Simões

Rua dos Comerciários, 155 IBES

Vila Velha ES Brasil

29108-490

e-mail: renasimoes@hotmail.com

Recebido em: 27 de janeiro de 2011.

Aceito em: 9 de fevereiro de 2012.

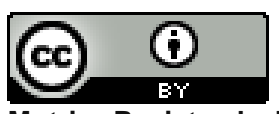

Motriz. Revista de Educação Física. UNESP, Rio Claro, SP, Brasil - elSSN: 1980-6574 - está licenciada sob Creative Commons - Atribuicão 3.0 